\title{
Fiscal Multipliers in Bad Times: Does the Nature of a Recession Matter?
}

\author{
NiCOLAS BORSOI* \\ Vladimir K. TEles*
}

\begin{abstract}
The literature measuring the magnitude of the fiscal multiplier has a considerable consensus that the stimulative effects of fiscal instruments depends on the current state of economic activity, whether it is expanding or facing a recession. However, none of the previous works studied how the nature of an economic downturn, if the economy is facing an adverse supply/demand shock, affects the effectiveness of fiscal expansions. We introduce in a simple New Keynesian model with a rich description of fiscal policy, the assumption of imperfectly informed policymakers (fiscal and monetary) to approach the question. Our results point out the existence of disparate effects of fiscal policy depending on whether the economy is facing a demand or a supply recession. Yet, we find out that cuts in taxes are an effective tool to counter the effects of adverse shocks on economic activity and aggregate consumption.
\end{abstract}

Keywords: Fiscal policy, fiscal multipliers, recession

JEL Codes:

\section{Introduction}

A recent central issue facing macroeconomics is the size of the impact of fiscal policy. In this regard, there is a general consensus in time series studies - as in the works of Auerbach and Gorodnichenko (2012, 2017); Candelon and Lieb (2013); Owyang, Ramey, and Zubairy (2013); Ramey and Zubairy (2018) - that the fiscal multiplier is dependent on the current state of economic activity, i.e., the magnitude depends crucially on whether economic activity is expanding or receding, such fiscal multipliers are increased in a recession. However, at least to our knowledge, does not work explored the question on whether the nature

Submitted on 31 May 2018; Reviewed on 23 Dec 2019

* Sao Paulo School of Economics (FGV/EESP).

口vladimir.teles@fgv.br 
of the economy's state matters for the fiscal multiplier, i.e., does the initial disturbance, demand/supply shock, matters for the size of the fiscal multiplier? This is the question our work wants to address.

AS-DS model tells us that the nature of shocks issues: a fiscal expansion in the supply-recession is completely counter-productive: the resulting equilibrium presents an even higher inflation rate without significant output effects. In a demand recession, however, fiscal stimulus is welcomed, since it shortens the transition from aggregate to its natural level. As we know, some predictions of the Keynesian context do not generalize completely to a general equilibrium environment. So, we use the New Keynesian model with a rich set of fiscal instruments, adjusting for debt and output conditions, to answer the question "Does the nature of recession matter for the magnitude of the fiscal multiplier?"

The novelty assumption in our model is imperfect knowledge of policymakers about the current state of the economy. We introduce this feature through fiscal and monetary rules describing policy decisions in the model. We impose that authorities are unable to observe the output gap in the economy, only the steady state deviation of aggregate output, so that by observing the current slack of resources in the economy, authorities are unable to tell whether the recession is due to an adverse shift in aggregate supply or demand. And why do we think this question is important? It conveys the important message that policymakers must understand well the nature of a recession hitting the economy before putting forward stimulative fiscal policies.

Our results shows that tax multiplier is indeed shock-dependent. We have also found out that even in a recession, where tax stimulus is a tax authority, tax multipliers fall to negative territory. The explanation for it resides on the existence of forward-looking agents, who counters fiscal stimulus by means of consumption smoothing. Our work shows that, even in a model where considerable fraction of population is made up of agents that track current income closely, governments must identify well the nature of a recession, and take into account the interactions of fiscal instruments and forward-looking agents' choices, before putting forward stimulative packages in a recessionary environment.

\section{The Model}

We develop a closed-economy New Keynesian model, inspired in Traum and Yang (2015), featuring two stochastic processes: one is a transitory total factor productivity (TFP) shock and the other is a monetary policy perturbation. The 
economy has a unit-measure continuum of households composed by two types of agents: Credit constrained households, which are a fraction $\mu$ of total population, and the remaining fraction $(1-\mu)$ is made up of saver households. We index a saver by the superscript $S$ and a non-Ricardian agent by the superscript $N$.

Savers, also described as Ricardian households, are forward-looking agents that can channel their savings to financial assets or physical capital. Also, they are sole owners of intermediary good firms, receiving profits in form of dividends. Credit constrained households (Non-Ricardian agents) cannot access capital or financial markets, and are subject to consume their current net-of-taxes income. One way to rationalize these agents is either the economy does not have a sophisticated financial system able to supply financial services for the entire population, or these agents do not posses enough net worth to be able to access financial intermediaries.

On the production sector, there is a continuum of intermediary firms $j \in[0,1]$ that operates in a monopolistically competitive industry, and each firm produces a differentiated good. Also, a perfectly competitive firm packs intermediary goods to produce an aggregate final commodity using a constant-returns-to-scale technology.

Furthermore, there are two government authorities: a Central Banker that manipulates interest rate through open market operations. The other authority takes ahead fiscal decisions, by using taxation and bond revenues to finance expenditure decisions, and follows fiscal rules to guarantee sustainability of public debt.

The model features a sole nominal friction in form of sticky prices, introduced via a Calvo (1983) process. Also, there are real frictions known to account for empirical features of business cycles (check, for instance, Christiano, Eichenbaum, \& Evans, 2005): external habit formation in preferences for households' consumption and adjustment costs in investments. We now describe the model in detail.

\subsection{Households}

Savers An arbitrary saver $j \in[0,1-\mu]$ maximizes the intertemporal utility function:

$$
\mathbb{E}_{t}\left\{\sum_{k=0}^{\infty} \beta^{k}\left[\ln \left(C_{t+k}^{S}(j)-\theta \tilde{C}_{t+k-1}^{S}\right)-\frac{L_{t+k}^{S}(j)^{1+\kappa}}{1+\kappa}\right]\right\}
$$


where $\mathbb{E}_{t}$ is the expectation operator, taken at date $t ; \beta \in(0,1)$ is the intertemporal discount factor; $\theta \in[0,1)$ is an external habit parameter; $\tilde{C}_{t}^{S}$ is the per-capita consumption of savers. Also, $\kappa \geq 0$ is the inverse of the Frisch labor elasticity.

The flow budget constraint of an arbitrary saver $j \in[0,1-\mu]$ is

$$
\begin{aligned}
\left(1+\tau_{t}^{c}\right) C_{t}^{S}(j) & +I_{t}^{S}(j)+B_{t}^{S}(j)=\left(1-\tau_{t}^{L}\right) w_{t} L_{t}^{S}(j) \\
& +\left(1-\tau_{t}^{K}\right) r_{t}^{K} K_{t-1}^{S}(j)+D_{t}^{S}(j)+Z_{t}^{S}(j)+\frac{R_{t-1} B_{t-1}^{S}(j)}{\pi_{t}},
\end{aligned}
$$

where $I_{t}^{S}(j)$ is the amount of final goods devoted by agent $j$ to investment; $B_{t}^{S}(j)$ is the amount of government bonds purchased by the household, with a fixed nominal return $R_{t} ; D_{t}^{S}(j)$ are dividends paid by intermediary firms; $Z_{t}^{S}(j)$ is the amount of government transfers; and $\pi_{t}=P_{t} / P_{t-1}$ is the gross inflation rate between periods $t-1$ and $t$. Notice that we assume that government taxes consumption, labor and capital incomes, and the tax rates are time-variant.

Capital stock law of motion is given by

$$
K_{t}^{S}(j)=\left(1-\delta_{0}\right) K_{t-1}^{S}(j)+\left[1-s\left(\frac{I_{t}^{S}(j)}{I_{t-1}^{S}(j)}\right)\right] I_{t}^{S}(j)
$$

where $s(\cdot)$ is a convex adjustment cost function, and we assume $s(1)=s^{\prime}(1)=0$ and $s^{\prime \prime}(1)=s>0$.

Credit Constrained Households In a similar way to Galí, López-Salido, and Vallés (2007), we assume there is a continuum of measure $\mu$ of households who do not posses any financial or physical assets. They have the same preferences as savers, but their budget constraint is limited by labor income and government transfers. For an arbitrary agent $i \in(1-\mu, 1]$, the flow real budget constraint is

$$
\left(1+\tau_{t}^{C}\right) C_{t}^{N}(i)=\left(1-\tau_{t}^{L}\right) w_{t} L_{t}^{N}(i)+Z_{t}^{N}(i)
$$

We assume that the government taxes credit constrained households in the same way as savers. And as a first approach, we assume in our benchmark model that the fiscal authority provides all households the same amount (homogeneous) of transfers, i.e., $Z_{t}^{S}=Z_{t}^{N}$. This assumption cleans the benchmark results from the effect of government using transfers to alleviate the inability of non-savers to engage into intertemporal transactions. 


\subsection{Production Sector and Pricing Decision}

Final Good Firm We assume there is a perfectly competitive firm whose objective is to choose the optimal allocation of intermediary goods to maximize profits. Final good $Y_{t}$ is produced by aggregation of intermediary goods $j \in[0,1]$ using a Dixit and Stiglitz (1977) technology:

$$
Y_{t}=\left(\int_{0}^{1} Y_{t}(j)^{\frac{1}{1+\eta^{p}}}\right)^{1+\eta^{p}}
$$

where $\eta^{p}$ is an exogenous price markup.

Intermediary Goods Firm The intermediary sector is comprised by a unitmeasure continuum of firms that produces different varieties in a monopolistically competitive market. A firm $i \in[0,1]$ production function is given by

$$
Y_{t}(i)=A_{t} K_{t-1}(i)^{\alpha} L_{t}(i)^{1-\alpha}
$$

These firms choose the amount of capital and labor inputs, $\alpha \in(0,1)$ is the capital remuneration share in total income, and the production function of these firms is subject to a common (temporary) TFP shock $A_{t}$. We assume that the logarithm of the shock follows a stationary $\mathrm{AR}(1)$ process:

$$
\log A_{t}=\rho_{a} \log A_{t-1}+\sigma_{a} \varepsilon_{t}^{a} \quad \text { where } \quad \varepsilon_{t}^{p} \sim \mathcal{N}(0,1)
$$

Pricing Decision Intermediary firms are subject to a Calvo (1983) pricing process: each period, a firm has a probability $\left(1-\omega_{p}\right)$ of being allowed to reset its price, independently of the amount of time elapsed since the last readjustment. Following Traum and Yang (2015), a firm that was not sorted to reset its price follows an indexation rule:

$$
P_{t}(i)=P_{t-1}(i) \pi_{t-1}^{\gamma_{p}} \bar{\pi}^{1-\gamma_{p}}
$$

where $\gamma_{p}$ measures the degree of indexation in the economy and $\bar{\pi}$ is the inflation rate at steady state (which by simplicity we assume $\bar{\pi}=1$ ).

A resetting firm chooses the price $P_{t}^{*}$, at time $t$, by seeking to maximize profits $^{1}$ while taking into account the chance that it may be unable to readjust

\footnotetext{
${ }^{1}$ Notice that intermediary firm maximizes nominal profits discounting them by savers (its owner) stochastic discount factor, given by the ratio between marginal utilities of wealth.
} 
price in the periods ahead:

$$
\max _{P_{t}^{*}} \mathbb{E}_{t} \sum_{k=0}^{\infty}\left(\beta \omega_{p}\right)^{k} \frac{\lambda_{t+k}^{S}}{\lambda_{t}^{S}}\left[\vartheta_{t+k} P_{t}^{*} Y_{t+k \mid t}(i)-T C_{t+k \mid t}(i)\right]
$$

where

$\vartheta_{t+k}=\left(\frac{P_{t+k-1}}{P_{t-1}}\right)^{\gamma_{p}} \bar{\pi}^{1-\gamma_{p}} \quad$ for $\quad k \geq 0 \quad$ and $\quad Y_{t+k \mid t}(i)=\left(\frac{P_{t}^{*}}{P_{t+k}}\right)^{-\frac{1+\eta^{p}}{\eta^{P}}} Y_{t+k}$

\subsection{Authority Decisions}

Traditionally, in the fiscal-DSGE literature, policy rules are set to respond to output gap in the economy. This assumption implies that a policymaker knows the flexible-price level of production. We introduce the assumption that authorities do not observe output gap, only the current deviation of output from steady state. So, we assume authorities observe:

$$
\hat{Y}_{t}=\hat{Y}_{t}^{g}+\hat{Y}_{t}^{n}
$$

where $\hat{Y}_{t}^{g}$ is the output gap, difference between current output and the flexibleprice level of production, and $\hat{Y}_{t}^{n}$ is log-deviation between natural output and its steady state value.

Remember that the output gap is given by the difference between contemporary output and the natural output. In our work, a demand shock is one in the nominal interest rate - in a flexible-price economy, the response of aggregate variables to a nominal shock is null-implying that in this recession, the natural output remains flat, so the output gap is positive $\hat{Y}_{t}^{g}>0$. On the other hand, in a supply recession, the flexible-price level of production falls more than contemporary output, so the output gap is negative. Therefore, the output gap conveys enough information about the nature of the recession, os that if our assumption does not hold, authorities would be able to distinguish whether the recession is caused by an adverse demand/supply shock.

Monetary Policy We present the log-linear Taylor rule for the nominal interest. Central Bank reaction is described by a smoothing parameter $\rho_{r}$, and by coefficients relating monetary policy decisions to contemporary log-deviations on inflation and output:

$$
\hat{R}_{t}=\rho_{r} \hat{R}_{t-1}+\left(1-\rho_{r}\right)\left[\phi_{\pi} \hat{\pi}_{t}+\phi_{y} \hat{y}_{t}\right]+\sigma_{m} \varepsilon_{t}^{m},
$$


where $\varepsilon_{t}^{m} \sim \mathcal{N}(0,1)$ is a standard Gaussian white-noise representing an exogenous shock to interest rate.

Fiscal Policy Fiscal authority raises taxes from consumption, labor and capital incomes, and issues bonds to pay for government consumption (which we assume non-productive, i.e., they do not change marginal products of intermediary firms), transfers to households, and interest payments. Each period, the authority is subject to the flow budget constraint:

$$
B_{t}+\tau_{t}^{K} r_{t}^{K} K_{t-1}+\tau_{t}^{L} w_{t} L_{t}+\tau_{t}^{C} C_{t}=\frac{R_{t-1} B_{t-1}}{\pi_{t}}+G_{t}+Z_{t}
$$

Aiming to reduce economic fluctuations, the fiscal authority can manipulate tax rates and expenditures. Following Zubairy (2014), we consider the following rules:

$$
\begin{gathered}
\hat{G}_{t}=\rho_{g} \hat{G}_{t-1}-\rho_{g b} \hat{B}_{t-1}+\rho_{g y} \hat{Y}_{t-1}+\sigma_{g} \varepsilon_{t}^{g}, \\
\hat{Z}_{t}=\rho_{z} \hat{Z}_{t-1}-\rho_{g z} \hat{B}_{t-1}+\rho_{z y} \hat{Y}_{t-1}+\sigma_{z} \varepsilon_{t}^{z}, \\
\hat{\tau}_{t}^{J}=\rho_{z} \hat{\tau}_{t-1}^{J}+\rho_{j z} \hat{B}_{t-1}+\rho_{j y} \hat{Y}_{t-1}+\sigma_{J} \varepsilon_{t}^{J},
\end{gathered}
$$

where $J=K, L$, and $\varepsilon_{t}^{I} \sim \mathcal{N}(0,1)$ for $I=g, z, k, l$ are Gaussian white-noise perturbations aimed to capture unexpected changes in the fiscal apparatus.

Changes in consumer tax rates are ruled out because there is a great amount of evidence - for instance, Zubairy (2014), Traum and Yang (2015), and Leeper, Traum, and Walker (2017) - discarding any relevant response of consumption tax rates to debt or output deviations for the US economy.

\subsection{Aggregation}

We now restrict attention to a symmetric equilibrium. ${ }^{2}$ Also, firms first order conditions (shown in the appendix) renders an identical marginal cost function, so they also present a common decision. Aggregation of individuals macroeconomic decisions renders the following aggregate variables:

Aggregate consumption:

$$
C_{t}=\int_{0}^{1} C_{t}(i) d i=(1-\mu) C_{t}^{S}+\mu C_{t}^{N}
$$

${ }^{2}$ Only between types, i.e., we do not assume that savers make the same decisions as non-savers, but we assume that every saver takes the same actions 
Aggregate labor:

$$
L_{t}=\int_{0}^{1} L_{t}(i) d i=(1-\mu) L_{t}^{S}+\mu L_{t}^{N} .
$$

Aggregate government transfer to households:

$$
Z_{t}=\int_{0}^{1} Z_{t}(i) d i=(1-\mu) Z_{t}^{S}+\mu Z_{t}^{N}=Z_{t}
$$

Aggregate capital:

$$
K_{t}=\int_{0}^{1-\mu} K_{t}(i) d i=(1-\mu) K_{t}^{S} .
$$

Aggregate investment:

$$
I_{t}=\int_{0}^{1-\mu} I_{t}(i) d i=(1-\mu) I_{t}^{S}
$$

Public debt:

$$
B_{t}=\int_{0}^{1-\mu} B_{t}(i) d i=(1-\mu) B_{t}^{S}
$$

Profits:

$$
D_{t}=\int_{0}^{1-\mu} D_{t}(i) d i=(1-\mu) D_{t}^{S} .
$$

Aggregate production function:

$$
\int_{0}^{1} Y_{t}(i) d i=Y_{t} p d_{t}=A_{t} K_{t-1}^{\alpha} L_{t}^{1-\alpha}
$$

where $p d_{t}=\int_{0}^{1}\left(P_{t}(i) / P_{t}\right)^{-\left(1+\eta^{p}\right) / \eta^{p}} d i$ is the price dispersion in the economy.

Resource constraint of the economy is:

$$
Y_{t}=C_{t}+I_{t}+G_{t}
$$

Proceeding to quantitative exercises imposes finding the first order conditions characterizing the optimal decisions of agents, finding out values of some variables at the steady state, and log-linearizing the relevant equations for the economy dynamics. For a complete exposition of these details, the reader is referred to the Appendix. 


\section{Methodology}

\subsection{Calibration}

Our calibration was done by searching our parameters in fiscal-DSGE articles. Our parameter vector is comprised of 33 elements, and there are five fiscal variables at the steady state to be set.

The fiscal variables at the steady state - namely, the ratios of government spending and government debt to GDP, the tax rates for labor and capital incomes, and the tax rate over private consumption - are fixed by using an U.S. quarterly sample from 1983:Q1 to 2008:Q1 at federal level (excluding subnational taxation, expenditures and public debt). We calibrate these values to their sample means, and in order to be consistent to the closed economy nature of our model, we define aggregate output as the sum: Consumption + Investment + Government Expenditures.

We chose this sample period because the model is best characterized as an economy operating under active monetary and passive fiscal policies, in the sense of Leeper (1991). There is some evidence - for instance, Davig and Leeper (2011) - showing that U.S. joint fiscal and monetary regime for this time span is better characterized by a regime of active monetary and passive fiscal policies. The values considered are:

- Government-consumption-to-GDP ratio: $G / Y=8.95 \%$.

- Debt-to-GDP ratio: $B / Y=38.20 \%$.

- Labor income tax rate: $\tau^{L}=20.9 \%$.

- Capital income tax rate: $\tau^{K}=19.60 \%$.

- Consumption tax rate: $\tau^{C}=1.49 \%$.

Some parameters are common in the business cycle literature. The discount factor $\beta$ is set at 0.99 . Since this is a quarterly model, the steady state interest rate is approximately $1 \%$ per quarter (equivalently, $4 \%$ p.a.). The steady state rate of depreciation of capital stock, $\delta_{0}$, is set at $2.5 \%$, so that, in the long run, capital stock depreciates $10 \%$ per year. The capital share of national income $\alpha$, is fixed at 0.36 , meaning that approximately two thirds of all economy resources is paid in form of wages. Finally, we have price mark-up of intermediary firms, which is set at 14\%, a value attributed to Basu and Fernald (1995). Other parameters, despite the widespread use in business cycle works, have less consensual values than those before. These parameters are: the external habit 
formation in consumption $\theta$, the inverse of the Frisch elasticity of labor $\kappa$, the parameter $s$ governing the adjustment cost of investment at steady state, the coefficient related to the degree of indexation in firms price readjustment $\gamma_{p}$, and the probability of a firm being able to reset price $\omega_{p}$. We choose these parameters to the closest model of ours, which is Traum and Yang (2015). The parameters related to the generating process of the productivity shock are taken from Zubairy (2014).

The share of rule-of-thumb consumers $\mu$ presents a great dispersion of estimates in the literature, so in order to be conservative, we stick to the IMF estimate, as cited in Coenen et al. (2012), and fix it at 25\% percent. Finally, there are the parameters governing the policy decisions of the model: fiscal instruments law of motion and the Taylor rule. These parameters are taken from the work of Zubairy (2014), who used Bayesian methods to estimate these rules for the U.S. economy. A table summarizing all the values used to calibrate the model can be found in the appendix.

\subsection{Fiscal Multiplier}

Traditionally, in articles analyzing fiscal multipliers, the fiscal multiplier is measured as the ratio between the change in output and the variation in the government tool (transfers, tax rates, etc), after applying an exogenous shock to the fiscal instrument of interest. In our model, this method implies that the fiscal authority surprises agents with stimulative actions at the onset of a crisis. We depart by measuring a passive fiscal multiplier: we insert the fiscal rules in the model (that are carrying the information on how fiscal tools have been managed historically), and realize the following exercise:

Generate an adverse demand shock - an exogenous positive change in the nominal interest rate - or a negative supply shock - a negative variation in firms' $\mathrm{TFP}$ - and save the impulse responses of macroeconomic variables (aggregate output and aggregate consumption, to be more specific). The baseline scenario, called no adjustment, is defined as the economic trajectory when fiscal instruments respond only to debt, and no output stabilization is pursued, this is done by setting $\rho_{g y}=\rho_{z y}=\rho_{k y}=\rho_{l y}=0$.

The other scenarios, with fiscal instruments used to smooth economic fluctuations, are constructed by turning off the debt parameter of the tool of interest, while preserving the debt coefficient, and zeroing the output parameter of other tools. For example, the fiscal multiplier associated with government consumption is found by setting $\rho_{g b}=\rho_{z y}=\rho_{l y}=\rho_{k y}=0$. In the all-instruments scenario, 
we do not turn off any coefficients, and use the original fiscal rules of Zubairy (2014) ipsis litteris.

The fiscal multiplier is measured as the present value of the difference, in $\%$ of the steady state value, between the impulse responses. Specifically, the fiscal multiplier for variable $\mathrm{X}$, at period $t$ is defined as

$$
\eta_{X, N}=\sum_{k=0}^{N} \frac{X_{t+k \mid f . p .}-X_{t+k}}{\left(\prod_{j=0}^{k} r_{t+j-1}\right) \bar{X}}
$$

where $X$ denotes the level of the macroeconomic variable of interest, $\bar{X}$ the steady state value, $r_{t}=R_{t} / \pi_{t}$ is the real interest rate, and the subscript $f . p$. is capturing the use of a fiscal instrument. For the instant multiplier $(N=0)$, we set $r_{t-1}=1$ (no temporal discounting). We also consider fiscal multipliers for different time horizons, and define the infinite-horizon multiplier as the one computed for 100 quarters, which is a sufficient period for the economy to return to the original steady state.

Before the results, two additional comments: first, the interest rate used to calculate the present value multiplier is the real interest rate measured in the correspondingly fiscal scenario. In other words, when calculating the fiscal multiplier for the situation where only government expenditures respond to output changes, we use the interest rate resulting from that model specification. Second, we compute five types of fiscal multiplier:

( $i$ ) Only government consumption responds to output deviations.

(ii) Only government transfers adjusts to output deviations.

(iii) Only labor income tax rate responds to output deviations.

(iv) Only capital income tax rate responds to output deviations.

(v) All fiscal instruments adjust to output deviations.

Finally, when describing the effectiveness of a policy, we focus on the infinitehorizon multiplier because this is a better measure on how much the authority is capable of moderating economic fluctuations. Also, we do not explicit write that a fiscal multiplier is measured in \% of steady state output. For instance, if the fiscal multiplier is $1 \%$, we will write that, under such instrument, the output is $1 \%$ higher than in the baseline scenario. 


\section{Results}

\subsection{Benchmark Results - Government Consumption Shock}

Before presenting our results for the fiscal multiplier, let's check the impulse response of the model to a positive unexpected change in government consumption. As said before, the calibration was made to give these figures a similar shape to those found in fiscal policy literature. We apply a $1 \%$ shock to the level of government consumption $\left(\varepsilon_{t}^{g}=1 \%\right)$. The set of impulse responses is found in Figure 1.

Classical results appear in the graphics: as government consumption goes up, so does aggregate demand. The existence of nominal rigidity implies some firms respond to the shock by increasing production. Since capital stock is fixed, firms start hiring more labor. Market clearing in labor market requires a higher real wage, and since there is a direct correspondence between labor input and marginal cost, marginal costs are higher too. The economy starts facing inflationary pressures, and to counter it, Central Bank reacts by raising nominal interest rates, and since the Taylor principle is respected, the real interest rate rises.

Increased wages and labor supplied creates a spike in labor income, resulting in bumped up consumption of credit-constrained households. On the other hand, the rise in real interest rate, and Ricardian equivalence ${ }^{3}$ discourage savers consumption. The share of non-savers is not sufficiently high to generate a positive response of aggregate consumption on instant zero, so aggregate consumption falls even on impact.

As time passes, the fiscal deficit, created by higher consumption expenditures, and increased interest burden - government interest payments are higher not only because public debt increases, as a side effect of the policy, but also because the cost of servicing debt rises after the Central Bank movement-has to be fought. The fiscal adjustment is implemented through reduced transfers to households, and increases in taxes on labor and capital income. These decisions reduce after-tax income available to households, which forces them to cut consumption and investment expenditures further, thus, offsetting the short-run stimulative effects of a shock in government consumption. As the stimulus languishes over time, the net effects of increased government expenditure eventually fall below the zero mark.

\footnotetext{
${ }^{3}$ Increases in the present value of government deficits must be offset by a rise in the present value of taxes, forward looking agents know that, and by means of consumption smoothing, cut current and future consumption plans, channeling these resources into saving.
} 

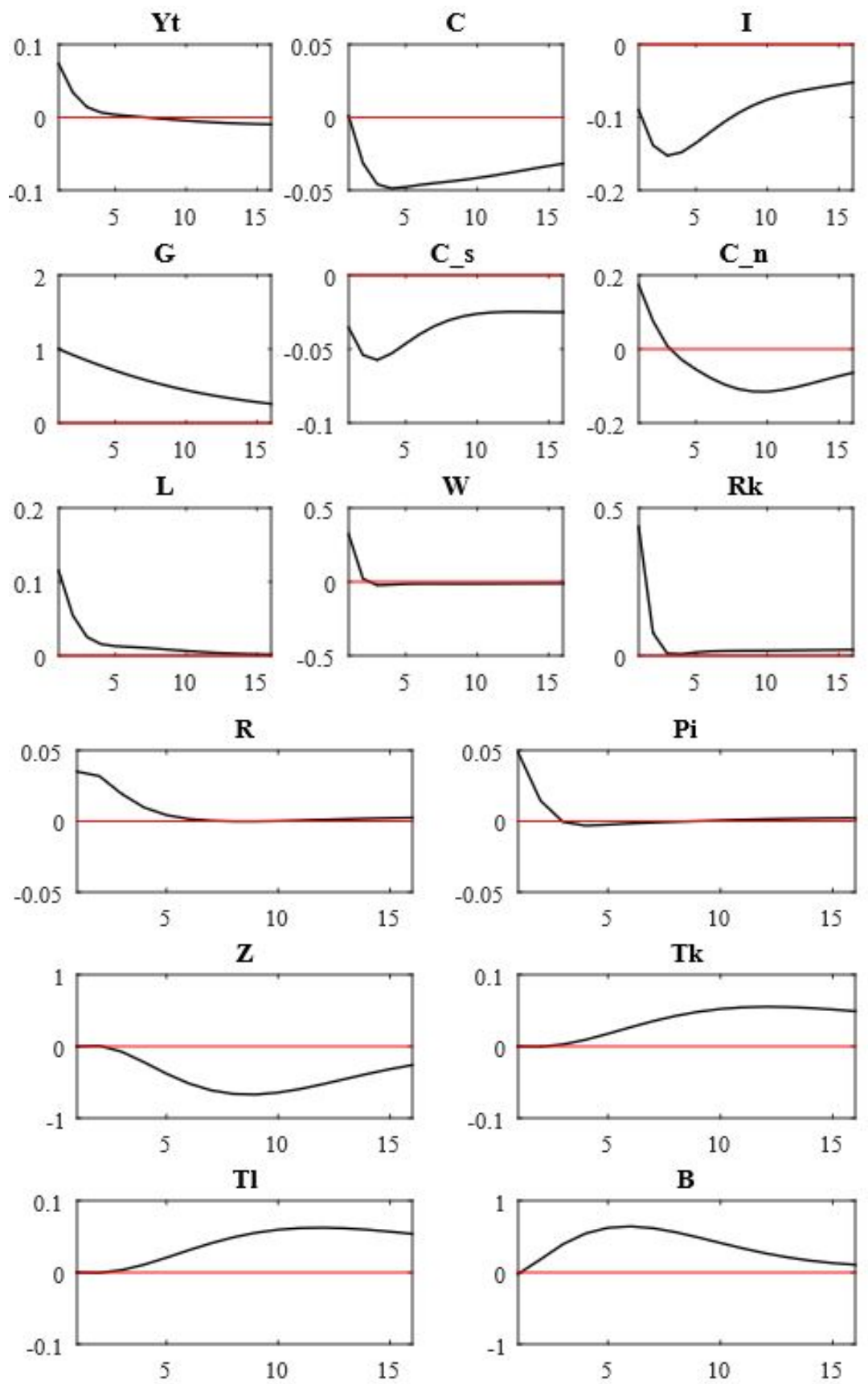

Figure 1. IRFs for a government spending shock. 


\subsection{Benchmark Results - Demand Recession}

The impulse responses for all options of fiscal stimulus are not shown, we display only the IRFs associated to the all-instruments-adjusting scenario.

We start by the fiscal multiplier in a demand-driven recession: the adverse event in this scenario is an increase in interest rate enough to cause an instantzero recession of $1 \%$ in the baseline scenario. This is considered a demand recession because, in spite of the decline in the economy's aggregate output, the flexible-price level of production is flat. The impulse responses are found in Figure 2.

On impact, the higher interest rate triggers consumption smoothing of savers, thus reducing the demand for final goods, and consequently, intermediary firms products. Nominal rigidity implies that some firms are unable to reset prices, so they react by cutting production, resulting in a lower demand for labor. Real wage declines, and given the complementarity between capital and labor in the production function, capital rent also falls.

Reduced wages trigger second-round effects in households consumption choices. The fall in consumption comes not only from savers, but also from credit-constrained households. The lower return on capital $\left(r_{t}^{K}\right)$ results in a drop in the amount of investment by savers. Facing a rise in the financing cost of public debt, fiscal authority cuts its expenditures, and raise the tax rates on labor and capital incomes, leading to a deeper fall in real wage and capital rent.

Overtime, with the exception of aggregate investment, variables monotonically return to steady state levels. The behavior of investment is explained by the fact that at approximately 4 quarters, the rise in the capital rent, and the recomposion of the capital stock implies that investment has to pick up before returning to equilibrium level.

Our numbers for fiscal multiplier are those in Table 1.

Table 1. Fiscal Multiplier (\%) - Demand-Driven Recession.

\begin{tabular}{|c|c|c|c|c|c|c|c|c|c|c|}
\hline \multirow{3}{*}{$\begin{array}{l}\text { Quarters } \\
\text { after the } \\
\text { shock }\end{array}$} & \multicolumn{5}{|c|}{ Aggregate Output } & \multicolumn{5}{|c|}{ Aggregate Consumption } \\
\hline & \multicolumn{5}{|c|}{ Which instruments? } & \multicolumn{5}{|c|}{ Which instruments? } \\
\hline & All & $G_{t}$ & $Z_{t}$ & $\tau_{t}^{L}$ & $\tau_{t}^{K}$ & All & $G_{t}$ & $Z_{t}$ & $\tau_{t}^{L}$ & $\tau_{t}^{K}$ \\
\hline instant & 0.00 & 0.00 & 0.01 & 0.00 & 0.00 & 0.00 & 0.00 & -0.02 & 0.00 & 0.00 \\
\hline 1 year & 0.02 & 0.00 & -0.03 & 0.03 & 0.01 & 0.00 & -0.03 & 0.15 & 0.05 & -0.03 \\
\hline 5 years & 0.07 & 0.00 & -0.34 & 0.11 & 0.05 & 0.01 & -0.13 & 0.13 & 0.17 & -0.05 \\
\hline infinite & 0.09 & -0.03 & -0.54 & 0.14 & 0.09 & 0.06 & -0.22 & -0.51 & 0.28 & 0.08 \\
\hline
\end{tabular}

Expenditure-side measures result not only in a deeper contraction of output, 

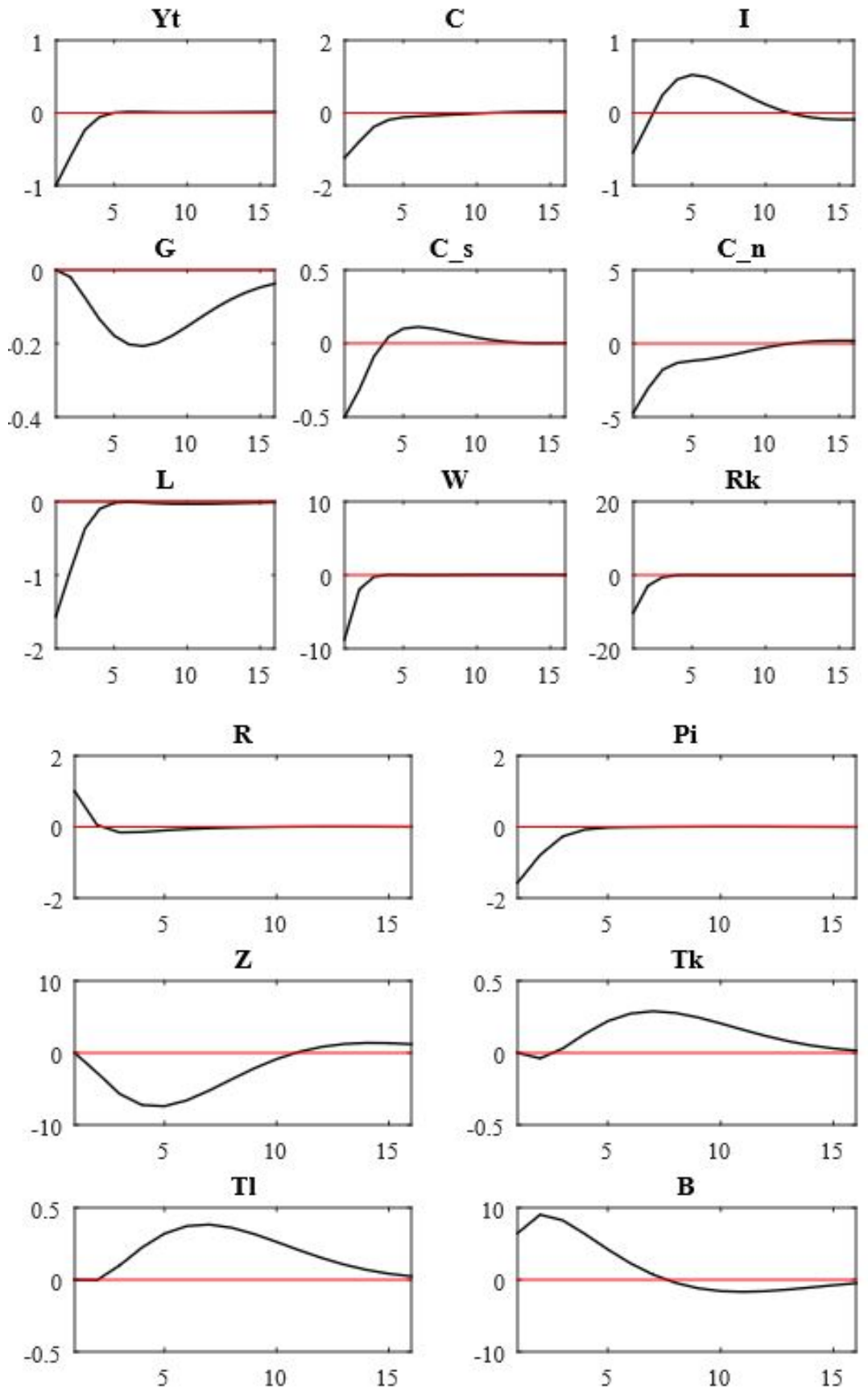

Figure 2. IRFs for a interest rate shock. 
$-0.03 \%$ for the government consumption, and $-0.54 \%$ in the case of transfer to households, but also in a steeper decline in households consumption $(-0.22 \%$ and $-0.51 \%$, respectively). When the government uses taxes, the most effective is using tax on labor income. Despite no relevant effect in the short run, by the end of the economy's transition path, the output was $0.14 \%$ higher. Using the capital tax rate is not different than a full-fledged fiscal posture: both measures reduces the severity of the recession by $0.09 \%$.

If fiscal authorities are worried about the welfare of citizens, loosely proxied by the behavior of aggregate consumption, the best alternative is to use labor taxes to reduce fluctuations. This option generates an overall effect of $0.28 \%$, while the tax rate on capital option delivers a $0.08 \%$ increase. Using a complete fiscal adjustment bumps aggregate consumption by $0.06 \%$.

These results goes in the opposite direction of our intuition: in a demand recession, when there is an excess supply in the economy, it should be expected that increased expenditures, by promoting an outward shift of the IS curve, should result in a smoother, not deeper, recession as our results show. The result about government consumption rests on the classical Ricarian equivalence. By raising government consumption, savers experience a negative wealth shock, so they smooth consumption by raising saving. Given that their consumption has the biggest weight on aggregate demand, the net effect of the policy is negative.

The result when government raises transfers to households is surprising: we expected non-savers to bump up consumption and take the economy out of the slump faster. However, according to our figures, when government raises transfers, the financing decision is a greater (relative to baseline's) increase in the tax rate on capital income. In response to reduced incentives on investing in capital, savers reduce investment further. The properties of production function implies a lower marginal product of labor, so that, in equilibrium, there is a greater fall in labor income. This is the driving force behind the drop in aggregate consumption, which combined with the fall in investment, puts the economy in a worse recession.

Why taxes are so effective on supporting aggregate output and consumption in a demand recession? The mechanism is equivalent for both types of taxation, so we pick labor tax first. The slash in labor tax implies a higher after-tax labor income (for credit constrained households, this is what mostly explains their consumption decisions), so the fall in Non-Ricardian households consumption is less pronounced than the baseline's. Thus, by counterbalancing the recessionary effect of higher interest rates, aggregate demand falls less when labor tax is cut. 
For the case of capital income tax, the explanation is equivalent, but the agents involved are savers, who enjoy a higher after tax capital income, resulting in a smaller drop in their consumption.

In the scenario of all fiscal instruments, fiscal reaction displays cuts in government consumption, and transfer to households jointly to cuts in taxation. The resulting net effect is that investment and non-savers consumption do not fall as much as in the baseline scenario, resulting in a smoother recession and a lower drop in aggregate consumption.

\subsection{Benchmark Results - Supply Recession}

Consider the case of a supply recession. We apply a similar method to the demand recession: generate an adverse shock in intermediary firms TFP enough to reduce output by $1 \%$ (instant zero) in the baseline scenario. In contrast to the demand-driven recession, the flexible-price level of output changes after this perturbation. The set of impulse responses is given in Figure 3.

On impact, lower productivity by intermediate goods firms decreases the marginal products of inputs, resulting in both lower real wage and capital rent. However, intermediary firms inputs depend on the output gap of the economy, not the output deviation per se. Due to nominal rigidity, some firms can not reset their prices, so, compared to the natural level of output, where firms set their prices freely, the fall in output is reduced, resulting in a positive output gap. Hence, intermediary firms inputs are above steady state, implying that real wages and capital rent stay above the zero axis for the whole recession.

Since the Phillips Curve shows a positive relation between inflation and output gap, the positive output gap is the fact explaining the inflationary process the economy suffers. The Central Bank reacts by raising interest rates, which depresses the consumption of savers. On the other hand, credit constrained households consumption booms because of steep increase in their net-of-taxes labor income.

Interestingly, the fiscal authority actually experience a lower public debt on impact. This is somewhat counter-intuitive, but can be explained by the surge in revenues due to higher inputs hiring by intermediary firms. Also, due to a below-steady-state public debt, the fiscal authority engages into an expansionary path, by raising expenditures and reducing taxes on labor and capital.

Overtime, except for public debt and government transfers, the variables monotonically return to steady state equilibrium. The erratic behavior of them reflects the initial responses of government instruments to a loose fiscal position, 

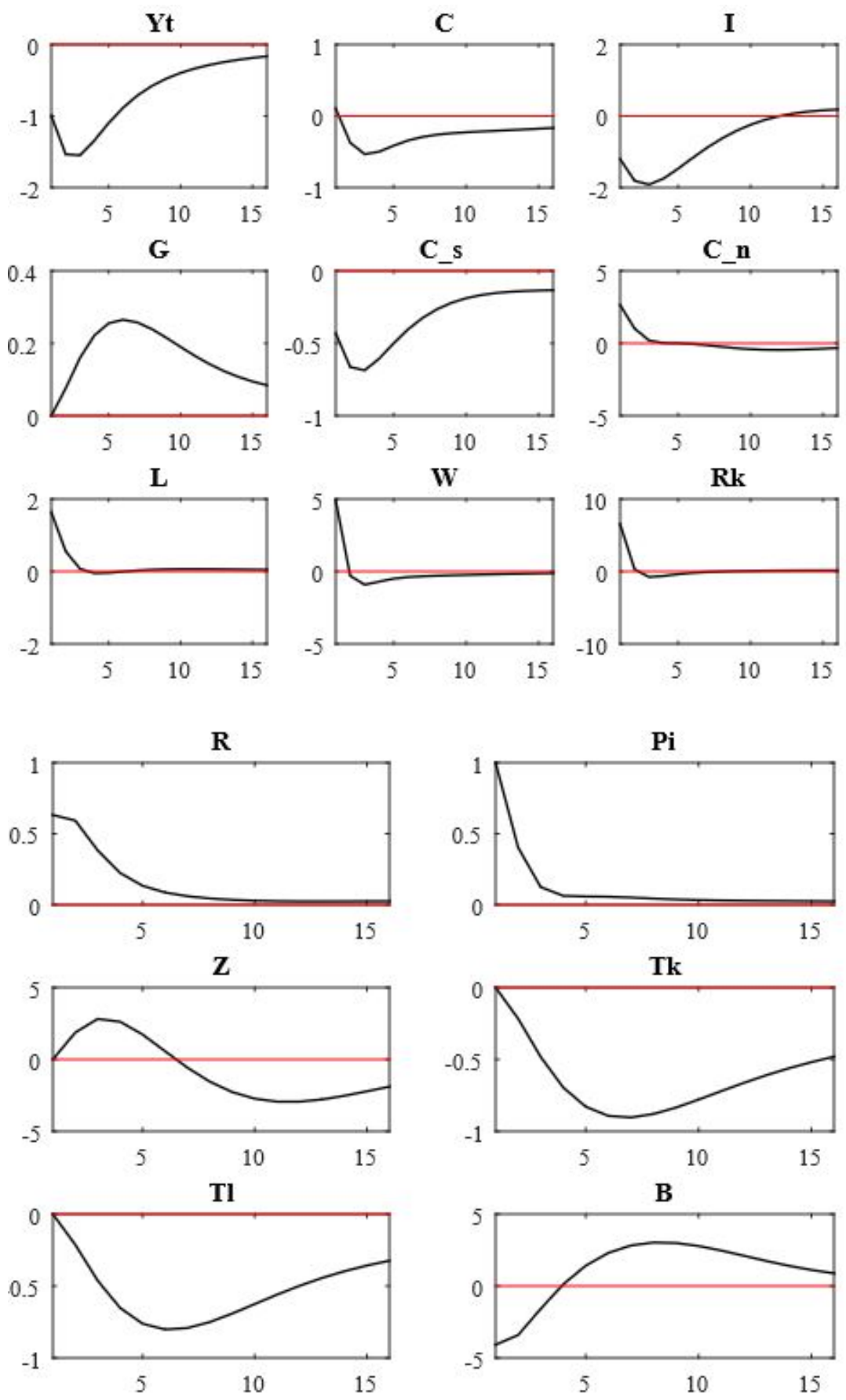

Figure 3. IRFs for a productivity shock. 
which by creating an accumulation of public debt intertemporally, requests a more austere fiscal position in mid-to-long term, which is done mostly by cuts on government transfers. The figures for fiscal multipliers in a supply recession are those in Table 2.

Table 2. Fiscal Multiplier (\%) - Supply-Driven Recession.

\begin{tabular}{|c|c|c|c|c|c|c|c|c|c|c|}
\hline \multirow{3}{*}{$\begin{array}{l}\text { Quarters } \\
\text { after the } \\
\text { shock }\end{array}$} & \multicolumn{5}{|c|}{ Aggregate Output } & \multicolumn{5}{|c|}{ Aggregate Consumption } \\
\hline & \multicolumn{5}{|c|}{ Which instruments? } & \multicolumn{5}{|c|}{ Which instruments? } \\
\hline & All & $G_{t}$ & $Z_{t}$ & $\tau_{t}^{L}$ & $\tau_{t}^{K}$ & All & $G_{t}$ & $Z_{t}$ & $\tau_{t}^{L}$ & $\tau_{t}^{K}$ \\
\hline instant & 0.00 & 0.00 & 0.01 & 0.00 & 0.00 & -0.01 & 0.00 & 0.02 & 0.00 & -0.01 \\
\hline 1 year & 0.05 & 0.00 & -0.01 & 0.02 & 0.03 & -0.03 & -0.02 & -0.03 & 0.04 & -0.07 \\
\hline 5 years & 0.41 & 0.01 & -0.22 & 0.29 & 0.22 & -0.05 & -0.16 & 0.09 & 0.30 & -0.22 \\
\hline infinite & 0.84 & -0.06 & -0.66 & 0.54 & 0.65 & 0.52 & -0.41 & -0.13 & 0.67 & 0.35 \\
\hline
\end{tabular}

The effective fiscal tools to stabilize aggregate output are cuts in taxes, again. Cuts in labor taxes reduce the recession by $0.54 \%$, and tax rates on capital income $+0.65 \%$. The rationale for this results is that the aforementioned mid-to-long-term fiscal adjustment is managed by cuts in households transfers, which opens up space for taxes to remain below steady state for an extended period. In the case of all instruments adjusting, the same explanation applies. The fiscal authority puts forward an aggressive fiscal stimulus in the short run, and manages the future fiscal adjustment through cuts in government consumption and transfers, and by maintaining taxes below their steady state rates, the output effects of fiscal policy stay in the positive side $(+0.84 \%)$.

If authorities opt for using households transfers or government consumption, the economic downturn worsens. By opting to use expenditures to stabilize aggregate output, the government builds up an even higher amount of public debt in the mid-to-long term, implying that higher taxes will be needed for an extended period. The fact that taxation will remain above steady state for a longer time creates a negative wealth effect on households, that by cutting consumption, slows the economic recovery, rendering a negative fiscal multiplier.

From the exposed, it is conclusive that governments can alleviate a supply recession if they are capable of reducing taxes, which reduces the distortionary effects on labor/capital supply, thus expanding the economy's aggregate supply ending up in a smoother recession.

Speaking about aggregate consumption, the numbers go hand-to-hand to the demand recession. It is always better to promote cuts in taxes: consumption is higher in the cases of all fiscal instruments adjusting $(+0.52 \%)$, lower labor taxes $(+0.67 \%)$, and lower capital taxes $(+0.35 \%)$. Lowering these taxes promotes a 
fall in the distortionary effects, and additionally, increase households' after tax income, creating a lower fall in aggregate consumption (relative to baseline's).

Using government consumption to support the economy, creates the Ricardian equivalence phenomena, which impacts negatively $(-0.41 \%)$ aggregate consumption. In the case of transfers, there is a positive short-run effect $(+0.02 \%)$, since households enjoy a higher income at that moment. However, as time passes, the necessity of bringing public debt down is accomplished by keeping taxes above their equilibrium levels, which reduces households net-of-tax incomes, thus slowing the recovery.

The figures show it is not good to use expenditure side measures: the fall in output is deeper not only in a demand shock, but also in a supply downturn. There is a unanimity on reducing labor and capital taxes to attenuate the recession. Overall, government stimulus is effective to reduce an economic recession when it is capable of promoting tax cuts: the reduced distortion by taxes expands the aggregate supply, and promotes an increase in households after-tax income, and since this is the biggest component of aggregate demand, the recession is smoother.

Our results suggest that governments should pursue reductions in labor tax, and should give up on the decision of using transfers to households as a mean of stabilizing output. When opting for the most effective tool, the fiscal authority must be well informed on the nature of the adverse shock hitting the economy, because the choice of the instrument result in different effectiveness of the stimulus. For example, choosing a full-adjustment in a supply recession reduces the recession by $0.84 \%$. In contrast, in a demand downturn, this option raises output by $0.09 \%$.

\subsection{Perfectly-Targeted Transfers}

Why should governments distribute resources to agents who have access to financial intermediaries? It should focus their grants on households that can not engage into intertemporal transactions, thus unable to smooth economic fluctuations. This assumption seems to reflect better the way on how governments should operate, and introducing it is pretty straightforward, we set $Z_{t}^{S}=0$ and solve the model in the same way as before. We call this extension as perfectly-targeted households transfers.

The magnitudes of the fiscal multipliers in both recession are those in tables 3 and 4 . 
Table 3. Fiscal Multiplier (\%) - Demand-Driven Recession.

\begin{tabular}{|c|c|c|c|c|c|c|c|c|c|c|}
\hline \multirow{3}{*}{$\begin{array}{l}\text { Quarters } \\
\text { after the } \\
\text { shock }\end{array}$} & \multicolumn{5}{|c|}{ Aggregate Output } & \multicolumn{5}{|c|}{ Aggregate Consumption } \\
\hline & \multicolumn{5}{|c|}{ Which instruments? } & \multicolumn{5}{|c|}{ Which instruments? } \\
\hline & All & $G_{t}$ & $Z_{t}$ & $\tau_{t}^{L}$ & $\tau_{t}^{K}$ & All & $G_{t}$ & $Z_{t}$ & $\tau_{t}^{L}$ & $\tau_{t}^{K}$ \\
\hline instant & 0.00 & 0.00 & 0.02 & 0.00 & 0.00 & 0.00 & 0.00 & -0.10 & 0.00 & 0.00 \\
\hline 1 year & 0.03 & 0.00 & 0.06 & 0.03 & 0.01 & 0.01 & -0.02 & 0.53 & 0.04 & -0.01 \\
\hline 5 years & 0.09 & 0.00 & -0.40 & 0.08 & 0.04 & 0.01 & -0.07 & 0.16 & 0.10 & -0.03 \\
\hline infinite & 0.12 & -0.01 & -0.70 & 0.11 & 0.07 & 0.07 & -0.11 & -0.55 & 0.16 & 0.05 \\
\hline
\end{tabular}

Table 4. Fiscal Multiplier (\%) - Supply-Driven Recession.

\begin{tabular}{|c|c|c|c|c|c|c|c|c|c|c|}
\hline \multirow{3}{*}{$\begin{array}{l}\text { Quarters } \\
\text { after the } \\
\text { shock }\end{array}$} & \multicolumn{5}{|c|}{ Aggregate Output } & \multicolumn{5}{|c|}{ Aggregate Consumption } \\
\hline & \multicolumn{5}{|c|}{ Which instruments? } & \multicolumn{5}{|c|}{ Which instruments? } \\
\hline & All & $G_{t}$ & $Z_{t}$ & $\tau_{t}^{L}$ & $\tau_{t}^{K}$ & All & $G_{t}$ & $Z_{t}$ & $\tau_{t}^{L}$ & $\tau_{t}^{K}$ \\
\hline instant & 0.00 & 0.00 & 0.02 & 0.00 & 0.00 & -0.01 & 0.00 & 0.06 & 0.00 & -0.01 \\
\hline 1 year & 0.06 & 0.00 & -0.08 & 0.03 & 0.03 & -0.02 & -0.02 & -0.16 & 0.04 & -0.07 \\
\hline 5 years & 0.47 & 0.02 & -0.46 & 0.31 & 0.22 & -0.06 & -0.17 & 0.16 & 0.27 & -0.21 \\
\hline infinite & 0.97 & -0.01 & -1.46 & 0.60 & 0.64 & 0.56 & -0.38 & -0.50 & 0.67 & 0.33 \\
\hline
\end{tabular}

It is pretty clear that the signs of the fiscal multipliers in a demand recession and in a supply recession are in agreement to the case of imperfect targeting of households transfers. The difference appears in the magnitude of them.

In a demand recession, using government consumption presents a insignificant fiscal multiplier $(-0.01 \%)$. Increasing transfers to households continues to be a bad decision, the multiplier remains in below-zero territory. As before, tax cuts are very effective: labor tax cut increases output by $0.11 \%$ (against $0.14 \%$ previously), and capital tax multiplier falls from $0.09 \%$ to $0.07 \%$. The consumption multipliers for a demand recession are in considerable agreement to the benchmark scenario, in the sense that expenditure-sided stimulus delivers a steeper fall in households consumption.

In a supply recession, our results show that the previous effective tools continue to perform well. Cuts in taxes present a positive fiscal multiplier: $0.60 \%$ for labor taxes ( $0.54 \%$ previously), and $0.64 \%$ for capital taxation. In the scenario of all instruments adjusting, we have a multiplier of $0.97 \%$, a considerable increase from the $0.84 \%$ in the case of imperfectly-adjusted transfers. Expenditures-side measures continue to render a negative result, government consumption has a multiplier of $-0.01 \%$. The most interesting result is the one surrounding government transfers, the multiplier goes from $-0.66 \%$ to $-1.46 \%$. Talking about aggregate consumption, the figures continue to favor a taxed-backed fiscal stimulus amid a supply recession. 
The explanation for the worst performance of government transfers in alleviating recessionary effects is due to the reduced amount of resources transferred to households is this scenario (a lower fraction of the population receives it), implying that a fiscal adjustment cannot be managed solely by reducing transfers. Hence, the authority needs to use taxes. While in the benchmark model, taxes monotonically return to steady state levels from below, in the perfectly-targeted specification, taxes are raised above their equilibrium values at approximately 3 years after shock. Hence, the deleterious effects of increased taxes explain the worst performance of transfers.

Overall, our results continue to present different effectiveness of fiscal stimulus depending on the nature of the recession, confirming the predictions before. The numbers still showing that expenditure-side stimulus are to be excluded from the set of tools that can help the economy to face a smoother recession.

\subsection{What is the Role of Government Debt?}

The excessive usage of government budgets to support economic activity in the years after the 2008 financial meltdown raised worries about elevated public debt in developed countries. The European sovereign debt crisis, that shook Europe mainly after 2010, is an extreme example of the problem: the PIIGSPortugal, Ireland, Italy, Greece and Spain - were unable to roll over public debt, subsequently having to put forward very austere government budgets, profound revisions in households benefits, and, additionally, receive relieving loans by multinational institutions like the IMF, the ECB and the European Financial Stabilization Mechanism (EFSM) to roll over their bonds.

We explore the problem of increased levels of public debt on the ability of fiscal policy to support economic activity by raising the steady state level of government-debt-to-GDP ratio from $39 \%$ to $74 \%$, which is the American average for a sample from 1947:Q1 to 2008:Q1, in the perfectly-targeted transfer specification. Yet, we are still considering that the fiscal authority is able to repay public debt (government debt returns to steady state level), and do not touch the issue of sovereign defaults arising as an equilibrium outcome.

Our measures for fiscal multipliers are those in tables 5 and 6 .

Beforehand, we should mention that recessions are slightly deeper in this scenario. If the same shocks of subsection 4.4 are applied to the no-adjustment specification (in which fiscal instruments react only to debt), the output fall goes from $1 \%$ to $1.04 \%$ in the demand recession, and in case of a TFP shock, the downfall rises from $1 \%$ to $1.02 \%$. 
Table 5. Fiscal Multiplier (\%) - Demand-Driven Recession.

\begin{tabular}{|c|c|c|c|c|c|c|c|c|c|c|}
\hline \multirow{3}{*}{$\begin{array}{l}\text { Quarters } \\
\text { after the } \\
\text { shock }\end{array}$} & \multicolumn{5}{|c|}{ Aggregate Output } & \multicolumn{5}{|c|}{ Aggregate Consumption } \\
\hline & \multicolumn{5}{|c|}{ Which instruments? } & \multicolumn{5}{|c|}{ Which instruments? } \\
\hline & All & $G_{t}$ & $Z_{t}$ & $\tau_{t}^{L}$ & $\tau_{t}^{K}$ & All & $G_{t}$ & $Z_{t}$ & $\tau_{t}^{L}$ & $\tau_{t}^{K}$ \\
\hline instant & 0.00 & 0.00 & 0.01 & 0.00 & 0.00 & 0.00 & 0.00 & -0.07 & 0.00 & 0.00 \\
\hline 1 year & 0.02 & 0.00 & -0.01 & 0.02 & 0.01 & 0.01 & -0.02 & 0.37 & 0.04 & -0.01 \\
\hline 5 years & 0.08 & 0.00 & -0.41 & 0.08 & 0.04 & 0.01 & -0.07 & 0.29 & 0.10 & -0.03 \\
\hline infinite & 0.09 & -0.01 & -1.23 & 0.10 & 0.06 & 0.06 & -0.11 & -1.06 & 0.16 & 0.04 \\
\hline
\end{tabular}

Table 6. Fiscal Multiplier (\%) - Supply-Driven Recession.

\begin{tabular}{|c|c|c|c|c|c|c|c|c|c|c|}
\hline \multirow{3}{*}{$\begin{array}{l}\text { Quarters } \\
\text { after the } \\
\text { shock }\end{array}$} & \multicolumn{5}{|c|}{ Aggregate Output } & \multicolumn{5}{|c|}{ Aggregate Consumption } \\
\hline & \multicolumn{5}{|c|}{ Which instruments? } & \multicolumn{5}{|c|}{ Which instruments? } \\
\hline & All & $G_{t}$ & $Z_{t}$ & $\tau_{t}^{L}$ & $\tau_{t}^{K}$ & All & $G_{t}$ & $Z_{t}$ & $\tau_{t}^{L}$ & $\tau_{t}^{K}$ \\
\hline instant & 0.00 & 0.00 & 0.01 & 0.00 & 0.00 & -0.01 & 0.00 & 0.04 & 0.00 & -0.01 \\
\hline 1 year & 0.06 & 0.00 & -0.06 & 0.03 & 0.03 & -0.02 & -0.02 & -0.10 & 0.04 & -0.07 \\
\hline 5 years & 0.47 & 0.02 & -0.43 & 0.32 & 0.22 & -0.07 & -0.17 & 0.14 & 0.28 & -0.22 \\
\hline infinite & 0.98 & -0.02 & -1.88 & 0.61 & 0.65 & 0.56 & -0.39 & -0.48 & 0.68 & 0.34 \\
\hline
\end{tabular}

Still, our measures for the fiscal multiplier show off a considerable agreement to those of previous section. In a demand recession, fiscal multipliers of expenditure tools continue to be in the negative side, and tax cuts still promote a positive fiscal multiplier: $+0.09 \%$ for the case of all instruments, $+0.10 \%$ in the case of labor tax, and $+0.06 \%$ for capital tax rates.

In a supply recession, fiscal multipliers practically mimics those of a lower debt economy: expenditure instruments generates the same negative effect, $-0.02 \%$ for government consumption, and $-1.88 \%$ in the case of households transfers. On the revenue sphere of fiscal policy, in concordance to previous fiscal multipliers, when all instruments respond to output deviations, there is overall effect of $+0.98 \%$, capital taxes result in a $0.65 \%$ positive multiplier, while labor taxes soften the recession by $0.61 \%$. The same reflections can be applied to aggregate consumption.

The general message is that the transmission channels of a fiscal stimulus in a recession remain the same in a high (repayable) public debt economy, but they tend be more ineffective, the multipliers are lower in eight out of ten situations for aggregate consumption, and in seven out of ten for aggregate consumption. The only instrument capable of smoothing the recessionary environment in both situations are again taxes. The fiscal multipliers for expenditure tools are always below zero. These results continues to show that choosing the most effective fiscal stimulus depends on the ability of the authority to correctly identify the 
adverse shock hitting the economy, since the instruments can have different performances depending on the recession hitting the economy. However, as a general message, fiscal stimulus in a supply recession are very welcomed because the expansionary effects of a fiscal stimulus present higher magnitude in this state.

\section{Conclusion}

In this work, we departed from the traditional approach to measure fiscal multipliers, and tried to quantify fiscal stimulus by the use of fiscal rules that makes use of the current knowledge on how governments historically managed fiscal stimulus, amid a recessionary environment with imperfectly informed policymakers. Building up on the consensus that fiscal stimulus are more effective in a recessionary economy, our approach sheds light on the question of whether the nature of a recession is important to quantify the magnitude of the fiscal multiplier.

We developed a New Keynesian model with imperfectly informed policymakers, and our answers point out that the nature of a recession is important to tell whether a fiscal stimulus is effective: the overall effect on aggregate output and consumption can be different, depending on whether the economy is suffering a supply or a demand recession. We found out that cuts in taxes are an effective tool to smooth recessionary fluctuations in the aftermath of an adverse shock. This happens not only because these reductions have positive supply side expansionary effects, but also due to increased households after-tax income, reduced taxes provide a source for aggregate demand expansion.

In contrast to the AS-DS intuition, our results point out that stimulative expenditure-side fiscal policy in a demand recession can be ineffective. By engaging into expenditure-side stimulus, and generating a negative wealth shock on forward-looking agents, the fiscal multipliers for the aggregate output and consumption are negative. In the old AS-DS models, households decisions track current income strictly, so any fiscal stimulus increasing aggregate output creates a positive feedback in aggregate demand, setting up an environment for the economy to quit recession faster than a no-stimulus situation. By introducing Ricardian agents, what happens to current income is not enough to change their decisions. Expectations play a major role in the economy dynamics, so, if the short-run stimulus on production comes at a cost of increased taxation, or reduced transfers, for a prolonged period, the stimulus by the fiscal authority may result in a net negative effect. 
Also, our work shows that fiscal stimulus in economies with higher debt is less effective than in lower debt ones. However, in our analysis, we did not focused on defaulting economies (this type of question is better suited for other classes of DSGE models), which may be a relevant concern when considering the interaction of fiscal stimulus and increased public debt levels.

Our paper is subject to some caveats: most results resides on labor income spiking in the aftermath of a stimulus. However, nominal rigidity on wage setting, which is a relevant feature of the economic environment, should mute this response, and introducing this feature may negatively affecting our measures for fiscal multipliers.

Also, we used a calibrated model to quantify fiscal multipliers, so our fiscal rules are context-invariant: the parameters values governing them are independent of the choice for fiscal stimulus. Our results would improve if Bayesian inference methods were used, since the estimation should present different parameter combinations depending on which instruments the authority decides to use. In this sense, the results of such alternative would be less naive than ours.

Finally, our comparison is based on two shocks, one defining a demand recession and the other a supply one. One interesting extension would be to introduce other types of shocks (intertemporal discount rate of households, a labor supply perturbation, etc), and check whether these demand and supply recessions present disparate effects for a fiscal stimulus. By doing so, we would be closer to understanding if our conclusions can be generalized to a complete set of shocks that throws an economy in a slump.

\section{References}

Auerbach, A. J., \& Gorodnichenko, Y. (2012). Measuring the output responses to fiscal policy. American Economic Journal: Economic Policy, 4(2), 1-27. http://dx.doi.org/10.1257/pol.4.2.1

Auerbach, A. J., \& Gorodnichenko, Y. (2017). Fiscal multipliers in Japan. Research in Economics, 71(3), 411-421. http://dx.doi.org/10.1016/ j.rie.2017.06.003

Basu, S., \& Fernald, J. G. (1995). Are apparent productive spillovers a figment of specification error? Journal of Monetary Economics, 36(1), 165-188. http://dx.doi.org/10.1016/0304-3932(95)01208-6

Calvo, G. A. (1983). Staggered prices in a utility-maximizing framework. Journal of Monetary Economics, 12(3), 383-398. http://dx.doi.org/ 10.1016/0304-3932(83)90060-0 
Candelon, B., \& Lieb, L. (2013). Fiscal policy in good and bad times. Journal of Economic Dynamics and Control, 37(12), 2679-2694. http://dx.doi .org/10.1016/j.jedc.2013.09.001

Christiano, L. J., Eichenbaum, M., \& Evans, C. L. (2005). Nominal rigidities and the dynamic effects of a shock to monetary policy. Journal of Political Economy, 113(1), 1-45. http://dx.doi.org/10.1086/426038

Coenen, G., Erceg, C. J., Freedman, C., Furceri, D., Kumhof, M., Lalonde, R., ... in 't Veld, J. (2012). Effects of fiscal stimulus in structural models. American Economic Journal: Macroeconomics, 4(1), 22-68. http://dx.doi.org/10.1257/mac.4.1.22

Davig, T., \& Leeper, E. M. (2011). Monetary-fiscal policy interactions and fiscal stimulus. European Economic Review, 55(2), 211-227. http:// dx.doi.org/10.1016/j.euroecorev.2010.04.004

Dixit, A. K., \& Stiglitz, J. E. (1977). Monopolistic competition and optimum product diversity. The American Economic Review, 67(3), 297-308. https://www.jstor.org/stable/1831401

Galí, J., López-Salido, J. D., \& Vallés, J. (2007). Understanding the effects of government spending on consumption. Journal of the European Economic Association, 5(1), 227-270. http://dx.doi.org/10.1162/ JEEA.2007.5.1.227

Leeper, E. M. (1991). Equilibria under 'active' and 'passive' monetary and fiscal policies. Journal of Monetary Economics, 27(1), 129-147. http:// dx.doi.org/10.1016/0304-3932(91)90007-B

Leeper, E. M., Traum, N., \& Walker, T. B. (2017). Clearing up the fiscal multiplier morass. American Economic Review, 107(8), 2409-2454. http://dx.doi.org/10.1257/aer.20111196

Owyang, M. T., Ramey, V. A., \& Zubairy, S. (2013). Are government spending multipliers greater during periods of slack? Evidence from twentiethcentury historical data. The American Economic Review, 103(3), 129-134. http://dx.doi.org/10.1257/aer.103.3.129

Ramey, V. A., \& Zubairy, S. (2018). Government spending multipliers in good times and in bad: Evidence from US historical data. Journal of Political Economy, 126(2), 850-901. http://dx.doi.org/10.1086/696277

Traum, N., \& Yang, S.-C. S. (2015). When does government debt crowd out investment? Journal of Applied Econometrics, 30(1), 24-45. http:// dx.doi.org/10.1002/jae.2356

Zubairy, S. (2014). On fiscal multipliers: Estimates from a medium scale DSGE model. International Economic Review, 55(1), 169-195. http:// dx.doi.org/10.1111/iere. 12045 


\section{Appendix A}

\section{A.1 Equilibrium Conditions}

\section{A.1.1 Savers' Problem}

Before proceeding to equilibrium conditions, we define $\lambda_{t}^{S}$ and $q_{t} \lambda_{t}^{S}$ as the Lagrangean multipliers associated to the budget constraint and the capital accumulation equation, respectively. Lowercase letters $x_{t}=X_{t} / Y_{t}$ are defined as the output adjusted level of the variable $X$. The first order conditions for savers are:

$$
\begin{aligned}
& \frac{1}{C_{t}^{S}-\theta C_{t-1}^{S}}=\lambda_{t}^{S}\left(1+\tau_{t}^{C}\right), \\
& \left(L_{t}^{S}\right)^{\kappa}=\lambda_{t}^{S}\left(1-\tau_{t}^{L}\right) w_{t}, \\
& \begin{array}{c}
1=\beta R_{t} \mathbb{E}_{t}\left[\frac{\lambda_{t+1}^{S}}{\lambda_{t}^{S} \pi_{t+1}}\right], \\
1=q_{t}\left[1-s\left(\frac{I_{t}^{S}}{I_{t-1}^{S}}\right)-s^{\prime}\left(\frac{I_{t}^{S}}{I_{t-1}^{S}}\right)\left(\frac{I_{t}^{S}}{I_{t-1}^{S}}\right)\right] \\
\quad+\beta \mathbb{E}_{t}\left[\frac{\lambda_{t+1}^{S}}{\lambda_{t}^{S}} q_{t+1} s^{\prime}\left(\frac{I_{t+1}^{S}}{I_{t}^{S}}\right)\left(\frac{I_{t+1}^{S}}{I_{t}^{S}}\right)^{2}\right], \\
q_{t}=\beta \mathbb{E}_{t}\left\{\frac{\lambda_{t+1}^{S}}{\lambda_{t}^{S}}\left[\left(1-\tau_{t+1}^{K}\right) r_{t+1}^{K}+q_{t+1}\left(1-\delta_{0}\right)\right]\right\} .
\end{array}
\end{aligned}
$$

Also, we need the capital law of motion:

$$
K_{t}^{S}=\left(1-\delta_{0}\right) K_{t-1}^{S}+\left[1-s\left(\frac{I_{t}^{S}}{I_{t-1}^{S}}\right)\right] I_{t}^{S} .
$$

\section{A.1.2 Non-savers' problem}

Non-savers face the same decision problem as savers, and we also use their budget constraint:

$$
\begin{array}{ll}
\frac{1}{C_{t}^{N}-\theta C_{t-1}^{N}}=\lambda_{t}^{N}\left(1+\tau_{t}^{C}\right), & \left(C_{t}^{N}\right) \\
\left(L_{t}^{N}\right)^{\kappa}=\lambda_{t}^{N}\left(1-\tau_{t}^{L}\right) w_{t}, & \left(L_{t}^{N}\right) \\
\left(1+\tau_{t}^{C}\right) C_{t}^{N}=\left(1-\tau_{t}^{L}\right) w_{t} L_{t}^{N}+Z_{t}^{N} . & \text { (B.C. }
\end{array}
$$




\section{A.1.3 Final goods firm's problem}

The objective of the firm is:

$$
\max _{\left\{Y_{t}(i)\right\}_{i=0}^{1}} P_{t} Y_{t}-\int_{0}^{1} P_{t}(i) Y_{t}(i) d i \quad \text { subject to } Y_{t}=\left(\int_{0}^{1} Y_{t}(i)^{\frac{1}{1+\eta^{p}}} d i\right)^{1+\eta^{p}} .
$$

The first order condition of the problem above renders the demand for intermediary goods:

$$
Y_{t}(i)=\left(\frac{P_{t}(i)}{P_{t}}\right)^{-\frac{1+\eta^{p}}{\eta^{p}}} Y_{t}
$$

Inserting this relation into the zero profit condition (since there is constant return to scale and perfect competition) of the firm, we have that

$$
P_{t}=\left(\int_{0}^{1} P_{t}(i)^{-\frac{1}{\eta^{p}}} d i\right)^{-\eta^{p}}
$$

\section{A.1.4 Intermediary firm's problem}

In order to pin down the firm's marginal cost function, the first problem to be solved is to minize expenditures for a given level of production:

$$
\min _{\left\{L_{t}(i), K_{t}(i)\right\}} W_{t} L_{t}(i)+R_{t}^{k} K_{t-1}(i) \quad \text { subject to } \quad Y_{t}(i)=A_{t} K_{t-1}(i)^{\alpha} L_{t}(i)^{1-\alpha}
$$

From the first order conditions of the problem, the solutions are returned into the production and the variables $K_{t-1}$, and $L_{t}$ can be written as functions of the intermediary firm's productivity-adjusted level of output:

$$
\begin{aligned}
L_{t}(i) & =\left(\frac{\alpha \omega_{t}}{(1-\alpha) r_{t}^{K}}\right)^{-\alpha} y_{t}(i), \\
K_{t-1}(i) & =\left(\frac{\alpha \omega_{t}}{(1-\alpha) r_{t}^{K}}\right)^{1-\alpha} y_{t}(i),
\end{aligned}
$$

where $y_{t}(i)=Y_{t}(i) / A_{t}$.

Finally, plugging the formulae above into the intermediary firms cost function, and taking the derivative with respect to $Y_{t}$, the marginal cost of the firm (common to all intermediary firms) is uncovered:

$$
m c_{t}=\left(\frac{\omega_{t}}{1-\alpha}\right)^{1-\alpha}\left(\frac{r_{t}^{K}}{\alpha}\right)^{\alpha} \frac{1}{A_{t}}
$$




\section{A.1.5 Pricing decision problem}

First, notice that the problem can be rearranged:

$$
\max _{P_{t}^{*}} \mathbb{E}_{t} \sum_{k=0}^{\infty}\left(\beta \omega_{p}\right)^{k} \frac{\lambda_{t+k}^{S}}{\lambda_{t}^{S}} P_{t+k} Y_{t+k \mid t}(i)\left[\vartheta_{t+k} \frac{P_{t}^{*}}{P_{t+k}}-m c_{t+k}\right] .
$$

Solving the problem above, one gets the following result:

$$
\mathbb{E}_{t} \sum_{k=0}^{\infty}\left(\beta \omega_{p}\right)^{k} \lambda_{t+k}^{S} P_{t+k} Y_{t+k \mid t}(i)\left[\vartheta_{t+k} \frac{P_{t}^{*}}{P_{t+k}}-\left(1+\eta^{p}\right) m c_{t+k}\right]=0
$$

The aggregate price index will be given by

$$
\begin{aligned}
P_{t}=\left(\int_{0}^{1} P_{t}(i)^{-\frac{1}{\eta^{p}}} d i\right)^{-\eta^{p}}=\left(\left(1-\omega_{p}\right)\right. & \int_{0}^{1} P_{t}^{*-\frac{1}{\eta^{p}}} d i \\
& \left.+\omega_{p} \int_{0}^{1} \vartheta_{t}^{-\frac{1}{\eta^{p}}} P_{t-1}(i)^{-\frac{1}{\eta^{p}}} d i\right)^{-\eta^{p}} .
\end{aligned}
$$

Simple algebra gives us finally that

$$
\left(1-\omega_{p}\right)\left(\frac{P_{t}^{*}}{P_{t}}\right)^{-\frac{1}{\eta^{p}}}+\omega_{p} \vartheta_{t}^{-\frac{1}{\eta^{p}}}\left(\frac{P_{t-1}}{P_{t}}\right)^{-\frac{1}{\eta^{p}}}=1
$$

\section{A.1.6 Fiscal Policy}

To search the steady state equilibrium, we only need the flow budget constraint:

$$
B_{t}+\tau_{t}^{K} r_{t}^{K} K_{t-1}+\tau_{t}^{L} w_{t} L_{t}+\tau_{t}^{C} C_{t}=\frac{R_{t-1} B_{t-1}}{\pi_{t}}+G_{t}+Z_{t}
$$

\section{A.1.7 Aggregation}

The aggregate relations necessary for the computation of this economy's equilibrium are

$$
\begin{aligned}
& c_{t}=(1-\mu) c_{t}^{S}+\mu c_{t}^{N}, \\
& \ell_{t}=(1-\mu) \ell_{t}^{S}+\mu \ell_{t}^{N}, \\
& k_{t}=(1-\mu) k_{t}^{S}, \\
& i_{t}=(1-\mu) i_{t}^{S}, \\
& b_{t}=(1-\mu) b_{t}^{S},
\end{aligned}
$$




$$
\begin{aligned}
d_{t} & =(1-\mu) d_{t}^{S}, \\
y_{t} p d_{t} & =K_{t-1}^{\alpha} L_{t}^{1-\alpha}, \\
1 & =c_{t}+i_{t}+g_{t} .
\end{aligned}
$$

\section{A.2 Steady State}

By assumption, at the steady state, we have $s(1)=s^{\prime}(1)=0$, and $P_{t}^{*}=P_{t}=P_{t+k}$. The equations necessary for the definition of the model's steady state are:

$$
\begin{aligned}
& \lambda^{S}=\frac{1}{\left(1+\tau^{C}\right)(1-\theta) C^{S}}, \\
& \left(L^{S}\right)^{\kappa}=\lambda^{S}\left(1-\tau^{L}\right) w, \\
& R=\frac{1}{\beta}, \\
& q=1 \\
& r^{K}=\frac{R-\left(1-\delta_{0}\right)}{\left(1-\tau^{K}\right)}, \\
& i=\delta_{0} k, \\
& \lambda^{N}=\frac{1}{\left(1+\tau^{C}\right)(1-\theta) C^{N}}, \\
& \left(L^{N}\right)^{\kappa}=\lambda^{N}\left(1-\tau^{L}\right) w, \\
& \left(1+\tau^{C}\right) c^{N}=\left(1-\tau^{L}\right) w \ell^{N}+z, \\
& \ell=\left(\frac{\alpha w}{(1-\alpha) r^{K}}\right)^{-\alpha}, \\
& k=\left(\frac{\alpha w}{(1-\alpha) r^{K}}\right)^{1-\alpha}, \\
& m c=\left(\frac{w}{1-\alpha}\right)^{1-\alpha}\left(\frac{r^{K}}{\alpha}\right)^{\alpha} \\
& m c=\frac{1}{1+\eta^{p}},
\end{aligned}
$$




$$
\begin{aligned}
& z=\left(\frac{\beta-1}{\beta}\right) b+\tau^{K} r^{K} k+\tau^{L} w \ell+\tau^{C} c-g, \\
& c=(1-\mu) c^{S}+\mu c^{N}, \\
& \ell=(1-\mu) \ell^{S}+\mu \ell^{N}, \\
& c=1-g-i .
\end{aligned}
$$

\section{A.3 Log-Linearized System}

We define $\hat{x}_{t}=\ln x_{t}-\ln \bar{x}$ as the $\log$-deviation of variable $x_{t}$ from its steady state value $\bar{x}$. Along with the Taylor rule (10) and the fiscal rules (12)-(14), the log-linear conditions for analyzing the transition path of this economy are the folloing equations.

Consumption equation:

$$
-\hat{C}_{t}^{S}+\theta \hat{C}_{t-1}^{S}=(1-\theta)\left[\hat{\lambda}_{t}^{S}+\frac{\tau^{C}}{1+\tau^{C}} \hat{\tau}_{t}^{C}\right]
$$

Labor supply:

$$
\kappa \hat{L}_{t}^{S}=\hat{\lambda}_{t}^{S}+\hat{w}_{t}-\frac{\tau^{L}}{1-\tau^{L}} \hat{\tau}_{t}^{L}
$$

Euler equation:

$$
\hat{\lambda}_{t}^{S}=\hat{R}_{t}+\mathbb{E}_{t}\left[\hat{\lambda}_{t+1}^{S}-\hat{\pi}_{t+1}\right]
$$

Investment equation:

$$
\frac{\hat{q}_{t}}{s}=\left(\hat{I}_{t}-\hat{I}_{t-1}\right)-\beta \mathbb{E}_{t}\left[\hat{I}_{t+1}-\hat{I}_{t}\right]
$$

F.O.C. for capital:

$$
\begin{aligned}
\hat{q}_{t}=-\mathbb{E}_{t}\left[\hat{R}_{t}-\hat{\pi}_{t+1}\right]+\left(1-\beta\left(1-\delta_{0}\right)\right) \mathbb{E}_{t}\left[\hat{r}_{t+1}^{K}\right. & \left.-\frac{\tau^{K}}{1-\tau^{K}} \hat{\tau}_{t+1}^{K}\right] \\
& +\beta\left(1-\delta_{0}\right) \mathbb{E}_{t}\left[\hat{q}_{t+1}\right] .
\end{aligned}
$$

Law of motion for capital:

$$
\hat{K}_{t}=\left(1-\delta_{0}\right) \hat{K}_{t-1}+\delta_{0} \hat{I}_{t}
$$


Consumption equation:

$$
-\hat{C}_{t}^{N}+\theta \hat{C}_{t-1}^{N}=(1-\theta)\left[\hat{\lambda}_{t}^{N}+\frac{\tau^{C}}{1+\tau^{C}} \hat{\tau}_{t}^{C}\right] .
$$

Labor supply:

$$
\kappa \hat{L}_{t}^{N}=\hat{\lambda}_{t}^{N}+\hat{w}_{t}-\frac{\tau^{L}}{1-\tau^{L}} \hat{\tau}_{t}^{L} .
$$

Non-Ricardian budget constraint:

$$
\begin{array}{r}
\left(1+\tau^{C}\right) c^{N}\left[\hat{C}_{t}^{N}+\frac{\tau^{C}}{1+\tau^{C}} \hat{\tau}_{t}^{C}\right]=\left(1-\tau^{L}\right) w \ell^{N}\left[\hat{w}_{t}+\hat{L}_{t}^{N}-\frac{\tau^{L}}{1+\tau^{L}} \hat{\tau}_{t}^{L}\right] \\
+z \hat{Z}_{t}
\end{array}
$$

Production function:

$$
\hat{Y}_{t}=\hat{A}_{t}+\alpha \hat{K}_{t-1}+(1-\alpha) \hat{L}_{t}
$$

Intermediary firms optimal choice:

$$
\hat{K}_{t-1}+\hat{r}_{t}^{K}=\hat{w}_{t}+\hat{L}_{t}
$$

Marginal cost:

$$
\widehat{m c}_{t}=(1-\alpha) \hat{w}_{t}+\alpha \hat{r}_{t}^{K}-\hat{A}_{t} .
$$

Phillips Curve:

$$
\hat{\pi}_{t}=\frac{\gamma_{p}}{1+\beta \gamma_{p}} \hat{\pi}_{t-1}+\frac{\beta}{1+\beta \gamma_{p}} \mathbb{E}_{t}\left[\hat{\pi}_{t+1}\right]+\kappa_{p} \widehat{m c}_{t},
$$

where $\kappa_{p}=\frac{\left(1-w_{p}\right)\left(1-\beta \omega_{p}\right)}{w_{p}\left(1+\beta \gamma_{p}\right)}$.

Government budget constraint:

$$
\begin{aligned}
b \hat{B}_{t}+\tau^{K} r^{K} k[ & \left.\hat{\tau}_{t}^{K}+\hat{r}_{t}^{K}+\hat{K}_{t-1}\right]+\tau^{L} w \ell\left[\hat{\tau}_{t}^{L}+\hat{w}_{t}+\hat{L}_{t}\right] \\
& +\tau^{C} c\left[\hat{C}_{t}+\hat{\tau}_{t}^{C}\right]=\frac{b}{\beta}\left[\hat{R}_{t-1}+\hat{B}_{t-1}-\hat{\pi}_{t}\right]+g \hat{G}_{t}+z \hat{Z}_{t} .
\end{aligned}
$$

Aggregate consumption:

$$
c \hat{C}_{t}=(1-\mu) c^{S} \hat{C}_{t}^{S}+\mu c^{N} \hat{C}_{t}^{N} .
$$


Aggregate labor:

$$
\ell \hat{L}_{t}=(1-\mu) \ell^{S} \hat{L}_{t}^{S}+\mu \ell^{N} \hat{L}_{t}^{N}
$$

Aggregate resource constraint:

$$
\hat{Y}_{t}=c \hat{C}_{t}+i \hat{I}_{t}+g \hat{G}_{t}
$$

\section{A.4 Calibration}

The values used to parametrize the model are in Table A-1.

\begin{tabular}{|c|c|c|}
\hline Parameter & Value & Source \\
\hline$\beta$ & 0.990 & \\
\hline$\alpha$ & 0.360 & \\
\hline$\delta_{0}$ & 0.025 & \\
\hline$\mu$ & 0.250 & Coenen et al. (2012) \\
\hline$\eta^{p}$ & 0.140 & Basu and Fernald (1995) \\
\hline$\theta$ & 0.700 & Traum and Yang (2015) \\
\hline$\kappa$ & 2.400 & Traum and Yang (2015) \\
\hline$\omega_{p}$ & 0.700 & Traum and Yang (2015) \\
\hline$\gamma_{p}$ & 0.280 & Traum and Yang (2015) \\
\hline$s$ & 2.000 & Zubairy (2014) \\
\hline$\rho_{a}$ & 0.790 & Zubairy (2014) \\
\hline$\sigma_{a}$ & 0.025 & Zubairy (2014) \\
\hline$\rho_{r}$ & 0.600 & Zubairy (2014) \\
\hline$\phi_{\pi}$ & 1.670 & Zubairy (2014) \\
\hline$\phi_{y}$ & 0.090 & Zubairy (2014) \\
\hline$\sigma_{m}$ & 0.160 & Zubairy (2014) \\
\hline$\rho_{g}$ & 0.920 & Zubairy (2014) \\
\hline$\rho_{g b}$ & 0.009 & Zubairy (2014) \\
\hline$\rho_{g y}$ & -0.040 & Zubairy (2014) \\
\hline$\sigma_{g}$ & 0.015 & Zubairy (2014) \\
\hline$\rho_{z}$ & 0.640 & Zubairy (2014) \\
\hline$\rho_{z b}$ & 0.439 & Zubairy (2014) \\
\hline$\rho_{z y}$ & -0.079 & Zubairy (2014) \\
\hline$\sigma_{z}$ & 0.054 & Zubairy (2014) \\
\hline
\end{tabular}

Table A-1. Values used to parametrize the model.

(Continue on next page) 
Table A-1. Values used to parametrize the model. (Continued)

\begin{tabular}{ccc}
\hline Parameter & Value & Source \\
\hline$\rho_{k}$ & 0.910 & Zubairy $(2014)$ \\
$\rho_{k b}$ & 0.017 & Zubairy $(2014)$ \\
$\rho_{k y}$ & 0.148 & Zubairy $(2014)$ \\
$\sigma_{k}$ & 0.012 & Zubairy $(2014)$ \\
$\rho_{l}$ & 0.900 & Zubairy $(2014)$ \\
$\rho_{l b}$ & 0.020 & Zubairy $(2014)$ \\
$\rho_{l y}$ & 0.132 & Zubairy $(2014)$ \\
$\sigma_{l}$ & 0.009 & Zubairy $(2014)$ \\
\hline
\end{tabular}

